\title{
Thinking outside the box: galleries, museums and evaluation
}

\author{
Sheila Galloway and Julian Stanley* \\ University of Warwick
}

\begin{abstract}
Museums and galleries in the UK increasingly engage with educational and social concerns; this article refers to research to evaluate two such initiatives. Evaluation of the Museum and Gallery Education Programme Phase 2, funded by the Department for Education and Skills, ends in August 2004. The research partnership to evaluate the 'En-vision' pilot action research programme, established by Engage (the national association for gallery education) with support from the Calouste Gulbenkian Foundation, the Carnegie UK Trust and three Arts Council regional offices, will complete in 2005. The article explores some key methodological issues relating to evaluation in this developing field. The conclusions are not necessarily endorsed by these sponsors; they are the views of the authors alone.
\end{abstract}

Keywords: Evaluation, Museums, Galleries, Museums, Social Inclusion, Learning Outcomes, Cultural Policy

\section{Introduction}

This article considers contexts and methods for the evaluation of two innovatory programmes. To explore the challenges which such evaluation poses, the first section examines the changing role of museums and galleries and the place which evaluation has in their practice. This is followed by a resumé of relevant organizations and initiatives in the UK.

We turn then to the evaluation of the Museum and Gallery Education Programme Phase 2, outlining the programme's aims and explaining the evaluation challenges which it presents. We consider the learning outcomes and the types of data collected as evidence of outcomes. Some early findings are summarized.

The second programme discussed is the En-vision pilot programme, which has a social rather than educational purpose. We review some issues relating to galleries and museums and social inclusion and set out concerns in evaluating programmes such as this. A menu of creative approaches to evaluation is explained and we indicate some initial issues emerging in this programme.

The article concludes by drawing together certain features of the context and practice of evaluating innovatory programmes in museums and galleries and in which practitioners, so to speak, find themselves 'thinking outside the box'.

\section{The role of museums and galleries and the place of evaluation}

Museums, galleries and archives in the UK are increasingly engaging with educational and social concerns and are frequently given the opportunity to take on objectives which derive from these agendas. Their activities are often conducted with the aim of achieving impacts beyond those associated with the more traditional roles and the services they formerly provided. A government agency, namely the Department of Culture, Media and Sport (DCMS), has been a key player in these developments. DCMS (previously Department of National Heritage) channels state funds to a large number of public bodies. The institution and development of DCMS, since the coming to power of the Labour government in 1997, has 
confirmed long terms shifts in the way in which public funding of culture is legitimated and regulated by government in the UK. Older notions of public subsidy to culture and the arts have been displaced by a growing emphasis on public investment in the creative and cultural industries, performance indicators and the promotion of public access and educational opportunities (see Garnham, 2001 for further discussion of these aspects of state cultural policy in the UK).

During the 1990s museums and galleries faced numerous pressures to ensure value for money, generate income, attract more visitors and improve services. A review of the decade's policy climate describes the period $1993 / 4$ to $1998 / 9$ as one of transition: 'the end of the old order and the beginning of the new' (Selwood, 2001b:1). Meanwhile the 'new museology' was pointing to ways in which museums and galleries could contribute positively to social change and to widening access to collections (Vergo, 1989; Mayrand,1985).

Policy trends and funding opportunities since 1997 have prioritised education and social inclusion and signalled the part which museums and galleries can play in these areas (Anderson, 1997a; Lawley, 2003; Hooper-Greenhill, 2004). Moving on from established outreach and community-focused activity, many institutions have become actively involved with other agencies, notably through the wide range of urban regeneration programmes. New, sometimes shifting, configurations of institutions have been encouraged by government, as in Creative Partnerships, a major initiative targeted at relatively deprived zones, providing substantial funds for joint creative projects run by schools and 'creative organizations'. Some initiatives have, following a general trend in England, been given a regional character. We summarize in the following section some key players and programmes currently influencing work in galleries and museums.

Policy trends can require museum and gallery staff to address more (and more directly) educational outcomes or the social effects of particular projects. Some large museums and galleries have dedicated education units with professional staff who have built up expertise in the planning and delivery of projects and sometimes in evaluation methods. However, the scene is very mixed. This reflects the 'pluralistic yet fragmented and patchy nature of the service provision in Britain as a whole' (Kawashima, 1997). Provision by museums of educational activities has also been described as 'patchy, ranging from the outstanding to the mediocre' (DCMS and DfEE, 2000).

Other researchers have observed a discrepancy between the high quality teaching and learning associated with some museums and galleries as against a 'rudimentary' provision of educational opportunities generally (Research Centre for Museums and Galleries, 2002: 12-14). Many of those involved in 'delivering' educational programmes may be working in museums or galleries where expertise has been limited and budgets for such activities historically under-resourced. Moreover, experience of evaluating educational activity can be limited. Often there has, until recently, been little support for evaluation, traditionally characterized by a standard end-of-session feedback form.

An important feature of the programmes referred to in this article is that they have given staff in such locations the chance to develop expertise in delivering and evaluating such programmes. They have also drawn in many quite small museums and galleries, helping to build capacity in the sector.

For practical reasons, where a curator with perhaps two part-time staff is responsible for the collection, premises, outreach work, encouraging access, marketing, administration, and so on, then developing expertise in how to evaluate projects may not be seen as a priority deserving of staff time. In addition, inherent professional tensions may on occasion exist between the aims of being a custodian of artefacts and works or art, and those of exploiting them for educational or social purposes. Very small museums are sometimes partly or largely run by volunteers. A significant and long-standing characteristic of the sector (Office of Arts and Libraries, 1991), this may well encourage community involvement, but time for evaluation is likely to be limited in these circumstances.

The labour market plays its part: for some professional people working in the sector, employment contracts are short-term or uncertain, making it difficult for any small organization to capitalise on the skills which current staff are acquiring (Galloway et al., 2002; Selwood, 2001d: 354). For others, insecurity derives from local authority threats of budget and service 
reductions (Lawley, 2003). Salary levels are often modest as confirmed in a recent study for the Museums Association (IDS 2004). Freelancers in the cultural sector often lack time or funds to invest in their own professional development (Galloway et al., 2002).

A further challenge for local authority museums was the introduction of 'Best Value' requirements, and the use of indicators for museum services as for other local authority services. The Audit Commission, with representatives of the sector, produced these measures which Lawley (2003:81) summarises as 'clear policies, good access, high quality collections, user services and people management, leadership, accountability, sustainability and longtermism', citing also a survey for the Group for Museum Directors (2000) which records reduced staffing levels and lower status accorded those working in museums (Lawley, 2003: 76-7).

Such factors mean that the task of taking on wider educational or social roles requires commitment and energy from staff in museums and galleries. Evaluation, too, internal or external, requires commitment and energy, even when it is designed to be on-going, integral to a project, and to take as little time as possible.

DCMS has highlighted education as a powerful factor in combating social exclusion (DCMS 2000) and 'funding agreements are tied to the delivery of policy-related outcomes' (Hooper-Greenhill, 2004: 152). Providing the evidence for such outcomes cannot be taken for granted. Economou (2004) distinguishes between museum visitor research and evaluation studies, noting that

Remarkably few organizations in the cultural sector have actually developed systematic strategies for carrying out visitor studies and evaluation work. In some cases, evaluation of the new developments and of their impact is not undertaken at all or is limited to the personal feelings and impressions of the staff involved and to anecdotal evidence. In other cases, evaluation studies tend to be individual efforts of limited scope, without forming part of an overall plan or strategy and without use of their results to inform the working practices and approach of the organization. (Economou, 2004:31).

However, she observes that factors such as tight budgets, increased public accountability and also the growing professionalism in the cultural sector put pressure on staff in cultural organizations to 'document and justify their practices'.

Similarly, the Assistant Director of the Calouste Gulbenkian Foundation comments:

The arts possess certain qualities that enable them to reach and sometimes to affect the sources of disengagement in young people. The evidence for this, however, is invariably anecdotal or speculative. While this doesn't undermine the truth of it, it does make it more difficult to argue for further resources for this work from public funding bodies. (Richey, 2004: 51)

From another perspective Kawashima says that if local authority museums are to survive, they must show that they deliver more than just visitor numbers:

They will need to test themselves against broader, qualitative standards and make clear their contribution to wider strategic objectives. They must become more visible and articulate their wider societal role. (Kawashima, 1997:153)

Demarcating visitor research and evaluation studies is a first step. We would highlight also the distinction between feedback from visitors (which helps in improving a service and may contribute to evaluation of a given project), and the sort of evidence which can substantiate more general judgements about a series of projects or a wider programme or initiative.

Numerous research reports have tried to assess the economic and social impact of the arts since Myerscough (1988). In the 1990s, increased attention went to their social impact (Matarasso, 1997). Reeves (2002), reviewing this literature, discusses impact and value, and sets out many of the definitional difficulties confronting researchers. She gives some reasons for the lack of robust research and evaluation on the impact and value of arts projects and programmes: 
- Lack of interest by the arts world (outside the context of funding relationships) in developing evaluative systems through which to prove its value

- Evaluation regarded as additional, rather than integral to arts activity, requiring disproportionate resources in the context of most arts organizations' limited budgets

- A lack of a thorough and formal approach to evaluation

- Lack of planning norms for arts facilities, against which to measure the quality or quantity of provision

- Organizations' primary motivation for undertaking evaluation being to fulfil funders' objectives rather than evaluating the impact of their activity on a particular neighbourhood

- Data collection being perceived as a chore rather than a tool to help organizations improve their own practice

- Cultural resistance to, and negative perceptions of, evaluation by those involved in arts projects, who often regard it as intrusive

(Summarized from Reeves, 2002: 34)

Many of these observations are not limited to the cultural sector, but they will strike a chord with those familiar with evaluation as it has been viewed in 'the arts'.

The programmes discussed in this article differ in purpose and scale, but both prioritized evaluation from their outset, ensuring that the evaluative process was at the forefront of project leaders' thinking from the start and could be built into their planning.

\section{Key organizations and initiatives}

We outline here some of the key agencies and initiatives which create the context for the two programmes later discussed in detail.

The UK Government's Department for Culture, Media and Sport (DCMS) is responsible for policy in the cultural sector and was historically the prime source of funds to museums and galleries. The Department for Education and Skills (DfES) is responsible for the education system; previously it allocated minimal sums to museums and galleries, mainly through the Arts and Humanities Research Board. This has changed in recent years. In April 2002, the existing Arts Council of England (which disburses most government funds to arts organizations) and the Regional Arts Boards joined together to form a single development organization for the arts, now named Arts Council England. The Heritage Lottery Fund (HLF) has since the mid 1990s been an important additional source of funding to museums and galleries.

Three agencies play a part in the programmes we discuss. In 2000, DCMS created a new strategic national body called Resource: the Council for Museums, Archives and Libraries, bringing together these three domains. This was recently renamed as the Museums, Libraries and Archives Council (MLA). The national association for gallery education, Engage, has a membership of artists, curators, and educators in the UK and abroad and exists to promote greater understanding of and enjoyment of the visual arts. Finally, the Group for Education in Museums (GEM) was also involved in one of these programmes. The Carnegie United Kingdom Trust and the Calouste Gulbenkian Foundation are charitable bodies which support the arts, including the En-vision programme.

Recently several public funding allocations have been made to museums and galleries. Joint DCMS/DfES funding in 2003-2004 to a dozen partnerships between national museums and smaller regional institutions enabled them to deliver school education projects. The Renaissance in the Regions programme, managed by MLA, involves regional 'museum hubs' in researching Education Programme Development Plans (EPDPs) to deliver a comprehensive schools service. 
In March 2004 the DfES announced MLA's Inspiring Learning for All framework, offering museums a common evaluation framework to assess the impact of education programmes. In April 2004 DCMS and DfES together announced the allocation of £7 million in 2004-06 to strengthen the ability of museums and galleries to support children's and young people's education. In July 2004, the Chancellor of the Exchequer announced in the UK Government's Spending Review a rise in DCMS funds and the extension of Renaissance in the Regions to all nine English regions. What this means in practice is not yet clear.

DfES and DCMS consulted with the sector to prepare a joint Museums and Galleries Education Strategy, due to appear in Summer 2004. DCMS is preparing a policy statement to set out the role of museums in the twenty-first century, which will confirm education as a core function of museums and point to implications for the skills base of the museum workforce.

Creative Partnerships, jointly funded by DCMS and DfES, enables schoolchildren to develop creativity in learning. In 2002-2004 16 areas benefited, selected from some of the most economically and socially challenged neighbourhoods in England. Twenty additional partnership areas will be created by 2006. This is a further component in the context in which museums and galleries operate.

These recent initiatives demonstrate a commitment of substantial funds to museums and galleries. As with the allocation of public funds in other fields, there is a need to track the use of these funds, and to point to outcomes and good practice which can be shared across the sector. In both these endeavours, evaluation plays a part.

Some such programmes require a high level of risk-taking as practitioners in museums and galleries engage with young people in new ways. The title 'Thinking Outside the Box' adopts the phrase used repeatedly by participants at a project leaders' meeting to convey how they were having to think more fundamentally in planning and carrying out their various projects, and to accommodate a degree of risk in exploring unfamiliar territory. This is reflected in the telling comment which some project leaders used of themselves, or of their colleagues: 'We've never done this before'. Innovative work, as encouraged by both these programmes, requires approaches which are familiar with the shape of the 'box' but are not confined to its contours. In assessing work which aims to break new ground in this way, the evaluation process itself must take account of a project's individuality, recognising the risks involved as well as aiming for an overview of the programme. The first of the two programmes which we examine in detail has an educational purpose.

\section{Museums, galleries and education: a national programme}

DCMS (1999) recognized partnerships and resources 'Beyond the School', and against this background, Phase 1 of the Museum and Gallery Education Programme (19992001) funded 65 education projects to improve links between schools and museums and galleries ${ }^{1}$.

The Museum and Gallery Education Programme Phase 2 (MGEP2) was a £1 million educational programme funded in 2002-2004 by the Curriculum Division of DfES to bring together museums, galleries and schools to develop resources or schemes to support the learning of school pupils aged 5-16, with regard to the learning objectives of the National Curriculum, which in England has statutory status. Some of the participating museums and galleries were able for the first time to access and understand the curriculum objectives of schools.

130 projects were funded across England in a programme managed nationally by Resource, now the MLA, and Engage (for 16 gallery-based projects under the name ArtFULL). The nine regional MLA offices were invited to bid to participate in the MGEP2 programme. This was the first substantial educational programme in which the newly emerged MLACs were able to make and administer grants to museums in their local region. They were able to direct an educational programme in the light of their own regional priorities, contribute to the support and monitoring of activity and later to the dissemination of learning and advocacy of good practice. MGEP2 aimed to develop new partnerships and new audiences, funding projects to: 
- build on the success of MGEP1

- use the collections and exhibitions of museums and galleries to enrich the national curriculum

- contribute to raising standards of achievement amongst pupils

- ensure that more pupils and teachers benefit from access to objects and images from museums and galleries.

(DfES, 2003)

Phase 2 focused on pupils' achievement in the classroom and learning outcomes. The national evaluation of this phase sought to record, understand and assess how far individual projects achieved the goals they set themselves. Proposals were required to determine their own pupil learning outcomes from a menu of 'recognized' outcomes such as:

- increased learning within a subject area and understanding of connections between subjects

- fulfilment and satisfaction from achievement

- increased self-confidence and self-esteem

- increased cultural understanding and respect of and tolerance of others

- increased ability to work with others

- positive attitudes to the experience and a desire for further experiences

(DfES, 2003)

The research team also sought to recognize learning among teachers such as increased confidence, expertise and professional satisfaction. Other professional development took place among participating artists, museum and gallery staff and other adults and indeed within the evaluation team.

The interim evaluation report ${ }^{2}$ was summarised in Learning Through Culture is Working (DfES, 2004). The final evaluation report is scheduled for September 2004. Managing organizations plan further dissemination of MGEP2 to practitioners.

Hooper-Greenhill (2004:153-4) notes that there has been little research into the potential or character of learning in museums, archives and libraries'. The methodology for measuring the social and educational impact of work done in museums and galleries has not been clear, and no study 'has focused directly on the measurement of the outcomes and impact of learning across the museum, archive and library sector as a whole'. She observes that museums and galleries, traditionally 'open, informal and flexible learning environments', cannot simply adopt the types of assessment methods common in schools, because 'users have their own criteria for what counts as successful (museums, archives and libraries do not expect to have to 'fail' their users)' (Hooper-Greenhill, 2004: 160).

In seeking to record and analyse what has sometimes been seen, at times even vaunted, as immeasurable, one methodological challenge posed by MGEP2 was to assemble appropriate types of evidence. Another was to find ways to make judgments not only about individual projects, but also about types of project and about the programme as a whole. Inevitably, there were tensions between the general and the particular in the evaluation process.

We signal again important distinctions between large local authority and national museums and the wide variety of small museums and galleries (generally with no permanent collection) which operate in altogether different circumstances. Those differences affect both what it is realistic for a project to 'deliver', and also the ways in which evaluation takes place. This article cannot do justice to the matter of diversity, but it was a particular challenge of MGEP2 that its evaluation did seek to make some general judgments about common 
outcomes across a great diversity of projects and institutions.

\section{Evaluation themes and methodological challenges: what constitutes 'evidence'?}

Devolution to the nine regional agencies (and to Engage) was a key feature of MGEP2. ${ }^{3}$ One condition of funding was that at least $50 \%$ of the $£ 100,000$ allocated to a region had to be spent on small grants for partnerships between schools and museums and galleries. Some regions supported one major project with a number of smaller ones, while others funded many modest projects. The external evaluation therefore had to take account of a wide spectrum of activity. The intention was that expertise in the regions should help to

- raise awareness of the potential of museum and gallery education

- fund projects which have already forged good links with local schools

- provide advice and support and cascade good practice

(DfES 2003)

Working with museums and galleries is attractive to schools because it brings diversity into the curriculum. This diversity was enhanced by agencies seeking to spread the money widely, supporting small projects, sometimes costing just a few thousand pounds. Yorkshire, for example, funded 15 projects involving 25 separate museums, many of them small volunteerrun independent museums, though some were substantial institutions. Projects involved loan boxes, museum visits, musical performance and photography, and lasted from one morning to ten months. The ten East Midlands projects included the loan of authentic artefacts from many parts of the world, work with pupils with special needs, loan boxes with original World War 1 objects, a web-based project, an oral history project and one focusing on the Victorian origins of a school and its community. The sixteen gallery-based projects managed by Engage involved art forms from digital media to sculpture, usually giving pupils the chance to work with artists or other creative people.

Regional agencies adopted various ways of managing MGEP2 and supporting projects. Some appointed a temporary support/advisory post to help deliver projects and evaluate internally, while others assigned these tasks to an existing officer. Such posts varied in their remit and objectives; here again the external evaluation process recognised this variety (interim reports, observation at training sessions and meetings, and interviews, early and late, with these post holders were the data collected here).

Evaluation of MGEP2 took place at different levels using qualitative and quantitative approaches. First, the overall framework demanded a minimum of internal and external evaluation for every one of the projects, using questionnaires and formal project reports. Secondly, 53 projects were externally evaluated by the research team (the extent of this varying according to the profile of the particular project). These case studies supported a thematic analysis of learning processes and outcomes, set alongside the statistical evidence generated by the overall framework, permitting general judgments across the programme as a whole.

This strategy recognized the fundamental importance of diversity but also that it is reasonable to seek to provide general accounts of programmes and to find ways of making judgments about certain types of project, or indeed the projects more generally. That said, there has been some variety of evaluative practice within MGEP2 and one outcome of the exercise may be to describe alternative approaches to evaluation as well as giving a series of alternative models for project delivery which might be adopted or adapted by others.

In consultation with representatives from museums and galleries and funding agencies, the following research tools were designed to track all projects in a basic way:

Initial project description

Quarterly log of the project

Final report on completion of the project

Project portfolio 
Entry and simple questionnaires for all students/pupils

Simple questionnaire for all teachers, museum staff, assistants.

The quarterly logs, project descriptions, final reports and questionnaires gave a standard format for recording information for formative and summative evaluation, and leading to the aggregation of data nationally.

The project portfolio might, we envisaged, actually be a 'project box' or other repository of information. Whatever the format chosen by project leaders, we suggested that it might contain some or all of:

Copies of initial project descriptions, quarterly logs and final reports

Examples or copies of pupils' work - before and after

Staff diaries, student and teacher dated notes

Images/video/audio or other evidence of student responses

Statistical records of attendance and participation

Records of student or teacher responses

Plans, schedules, budgets and minutes of meetings

Records of training

Other internal evaluation records

Such a range of relevant data offered project leaders flexibility over how they chose to represent a particular project. It gave the chance to highlight 'non-standard' information: projects also drew on material like photographs loaned by pupils' families, copies of newspaper reports, letters from local residents and recordings of performances. In some cases, this bank of material now provides a strong base for subsequent professional development and some regional agencies have made opportunities for MGEP2 project leaders to share their experience with others who did not participate.

The evaluation sought further data as appropriate from the 53 selected projects through:

Interviews with project leaders before and after the projects

Interviews with teachers and pupils before and after the projects

Observation of sessions and performances in schools, museums and galleries

Examination of student work, student diaries, teacher and staff diaries, video material and assessment data (teacher or test)

By such means the evaluation process sought to do justice to the variety of activity, media and participants across the projects and to reflect the programme's breadth and depth.

\section{Learning outcomes}

DfES identified a range of possible and desirable learning outcomes for pupils. Part of our work as evaluators was to develop a common understanding of what might count as evidence of these learning outcomes. An indication of possible evidence matched against outcomes was prepared:

LEARNINGOUTCOMES

Increased learning within the subject area

Increased understanding of connections between subjects

Increased learning across subjects 
Possible evidence

Teacher assessment of student work - level changes

Quality of student work - before and after

Comparison with learning with classes not in project

Teacher and student judgments

Observation of activity

Evidence of response to different learning styles, e.g. object handling, thinking skills

New concepts, skills, knowledge

Greater complexity/challenge

\section{LEARNING OUTCOMES}

Increased self-confidence and self-esteem

Increased ability to work with others

Increased involvement in class, school community events

\section{Possible evidence}

Observation and recording of participation - video

Student reports, dated' notes

Teacher observation, dated notes

Developmental work

Group self-evaluation

Engagement - how personal is response, how complete

Concentration - how long was activity sustained for - how does this compare for individual or group

\section{LEARNING OUTCOMES}

The ability to make informed choices within and beyond the planned experiences Positive attitudes to the experience and a desire for further experiences Increased self-confidence and self-esteem

\section{Possible evidence}

Developmental work - notes, sketchbooks, drafts

Creative and original work - how varied is group response, how does response compare to conventional work

Student plans for learning - research or action plans

Response or requests for further opportunities - evidence of independent learning

Independence - what tasks/skills may have been carried out with no or less teacher support

(Stanley, 2003)

Project leaders were asked to articulate any unforeseen experiences or learning outcomes beyond those predicted in their original plans. There were valuable 'spin-off' effects and this 
programme can be seen overall as a catalyst within the sector as well as in the more specific area of contributing to pupil learning.

The main alternative approaches to assessing learning in galleries and museums are those developed by the Research Centre for Museums and Galleries, which focuses on generic learning outcomes (Hooper-Greenhill, 2004) and research by the National Foundation for Educational Research on the effects of arts education in secondary schools, along with work on initiatives developed to address disaffection among young people (Harland et al., 2000; Kinder and Wilkin, 1998; Kinder and Harland, 2004).

\section{Early findings}

Provisional findings from the interim report on MGEP24 (CEI, 2004; DfES, 2004) include the following:

- The questionnaire research suggests some progress on all the learning outcomes explored.

- In the eyes of Key Stage 2 Pupils, the activities seemed to be particularly successful in supporting and raising confidence, and providing opportunities for choice and satisfaction with their work.

- Design and delivery of projects between museums/galleries and schools is likely to require a common approach with regard to expectations of what pupils can learn and how they can learn. Where schools and museums are coming together for the first time, and where several schools combine together on a project, differences in expectations may be thrown into relief.

- A novel learning activity, taking place in a fresh environment, being led by new teachers is likely to be greeted positively by learners and by school teachers, most of whom responded well to the opportunities.

- Individual projects differ in their impact. Factors include: timing and pace, quality of teaching and overall design of the project.

- Many learners respond extremely well to the opportunity to work with artists. They experience a fresh, confident and non-directive approach. Artists appear to be motivated by the challenge and stimulation of working creatively with young people on short projects.

- There is evidence that in a well managed, well staffed project, young people will be motivated by being given more open-ended, creative learning tasks and will go on to achieve work which their teachers judge to be of a relatively high standard.

- Some projects provided inspiration for the lead teacher who welcomed and felt encouraged by the innovation in teaching and learning embodied in the project. However, it seems relatively unusual for projects to have a wider impact on other teachers and pupils in the school.

- Many schools found the logistics of organizing additional activities, journeys, meetings, cover (for teachers out of school) and specialised resources challenging.

The final report on MGEP2 will give the detailed statistical and thematic analysis, and a series of over fifty case studies.

\section{Galleries and their social purpose: the 'En-vision' pilot programme}

Where MGEP2 had educational aims, En-vision has a social purpose. Engage established this initiative originally with the support of funds from the Calouste Gulbenkian Foundation and Carnegie UK Trust, then gained support from Arts Council regional offices. The programme would stimulate new collaborative projects linking gallery staff with youth 
workers, artists, arts and community organizations, special support services and young people, some of whom are socially excluded or at risk of being so. Three pilot schemes in the West and East Midlands, and North West England 5 involve eight galleries, with partners including youth arts organizations, a pupil referral unit, local youth clubs, community organizations and several artists. The programme aims to foster social inclusion and encourage young people to participate in activities in galleries.

In the UK, national interest in the area of young people's voice and participation has grown in recent years, and En-vision is recognized as being at the forefront in this (DCMS, 2003: 12-14). En-vision's core values are:

\section{Our purpose}

- To promote practice which makes a positive and additional contribution to the inclusion of young people within galleries.

- To support galleries to create meaningful and beneficial opportunities for young people, and promote recognition of the role they can play in re-engaging and nurturing the skills and aspirations of young people experiencing social exclusion.

- To work within a spirit of collaboration and inclusion, ensuring that young people and key agencies who support young people's personal, social, educational and creative development are genuinely included within the development of all aspects of our work.

\section{Our practice}

To develop contracting examples of practice relevant to diverse venues which:

- Are rooted in relevant theory and research and are informed by examples of good practice from within abroad professional field supporting work with young people.

- Address key priorities/research questions within the national and local context.

- Prioritize effective documentation and evaluation.

- Address the professional development needs of all participating staff and facilitators.

- Are inspirational, and seek to ensure that the outcomes inform, and are permanently rooted in, future practice.

- Identify tangible sustainable approaches to engaging with young people.

- Nurture equal and positive partnerships and promote collaborative working practices.

- Promote the philosophy of broadening access to the visual arts for young people, and promote the ethos of a youth-friendly gallery throughout the culture of the whole organization.

- Share the learning benefits across a broad national level.

\section{Our relationships with young people}

- To maintain the specific contribution galleries can offer and promote quality experiences with practising artists, original work and cultural venues.

- To promote specific benefits for disadvantaged and marginalized young people

- To develop this work within the context of broader youth engagement/access 
strategies to support inclusion in mainstream or complementary provision, enlisting the support of other professionals and agencies where appropriate.

- To respond to young people in a responsible, professional and ethical manner, and work within appropriate policy, legislation and good practice guidelines.

- To commit to a youth-centred approach, ensuring that we prioritise the needs of participants, and that we support young people's genuine and active participation in the design and delivery of our work

(Engage, 2003)

\section{Social inclusion, galleries and museums}

Merriman (2000:2) points out that museums have always been associated with the elite and have excluded large sections of the population: to explore their full potential, 'we must now work to dismantle the cultural barriers that have been deterrents to wider participation in museums'. Young people's disengagement from cultural activities including involvement in galleries is well recognised, with galleries being less appealing than performance (Arts Council of England,1994). Willis (1990: 59) indicated the need for galleries and museums to de-institutionalise and offer young people 'some kind of psychological ownership'. The insufficient relevance of galleries to young people's lives was seen as a factor which discourages involvement, and research has been dominated by discussion of participatory activities (Harland and Kinder, 1999: 20). These authors argued however that the goal of cultural inclusion would also seem to demand the development of listening, viewing and critical skills necessary for audience access, as well as an awareness that audiences too make a vital contribution to arts experiences and cultural creativity'. The En-vision pilot projects and their evaluation are explicitly participatory but also offer opportunities for the development of critical faculties in respect of both the creation of artwork and the process of taking part in the evaluation.

The programme seeks to foster an 'active youth voice' in galleries. There is, in the pilot projects, an aspiration that young people will develop from being passive, short-term consumers of 'youth projects' to playing an active sustained role in some aspects of the work of galleries. Getting the young person into the building or the project is the first step, but funky on your flyer (Ings, 1999: 45) stressed the long-term nature of the process of 'bringing young people to the point of trusting cultural venues'. That is where the excitement lies and evaluating these projects should take account of the risks - artistic, social and organizational - which are part and parcel of the pilots. We may thereby improve understanding of how these factors affect the engagement of young people and their sustained involvement. Meanwhile, NFER's research identified three 'basic tools of repair' or features of successful initiatives for reengaging young people (Kinder and Wilkin, 1998, cited in Kinder and Harland, 2004)

Fostering inclusion and tackling barriers to the involvement of young people in the arts have become major policy strands, accelerated since 1997, especially after the creation of the Labour government's Social Exclusion Unit. The Policy Action Team 10 on the arts and sports recommended in 1999 that social inclusion should be an integral part of public policy programmes. Building on PAT 10 proposed action plans to include people from ethnic minority groups and people with disabilities within cultural policy, a commitment reinforced in Culture and Creativity: the Next Ten Years (DCMS, 2001). However, the barriers and deterrents to the engagement of young people in galleries are diverse and often deep-seated. They can be social (e.g. related to social class, parental influence and peer pressure), physical (e.g. matters of travel, cost and lack of time), or psychological (e.g. the view that 'the arts' are irrelevant and culturally exclusive) (Harland and Kinder, 1999).

There are, meanwhile, quite fundamental questions which should not be disregarded about how appropriate and realistic it is to expect organizations within the sector to address multiple deprivation and deep-seated social concerns. For some galleries, the very process of recruiting young people likely to benefit from the opportunities which En-vision offers has itself proved far from simple. It has also been suggested that practice in museums and 
galleries regarding social inclusion projects is 'not based on sound foundations':

Either it stems from the collective memory of curators that has been passed from generation to generation, without being questioned. Or it is based on an unrealistic idea of what museums and galleries can achieve - reflecting the aspirations of curators and educators, rather than things they can deliver.

(Newman, 2002: 29)

The sector has in Sandell's view (2003: 52) had insufficient guidance on working on inclusionled projects. Assessing work under the broad heading of 'the impact of the arts', Shaw described how evaluation studies need to address actual experience, noting that the arts funding system and arts organizations recognise the need for "proof that the arts have made a difference' in order to secure better resources from the state. However:

A search commissioned by PAT 10, for 'robust research' into the role of the arts and sport in neighbourhood renewal, unearthed dozens of reports of activity, but few that could be described as robust. Too many evaluations overemphasise the positive aspects of a project and disregard the negative. The reasons why are obvious: those who have worked hard on a project do not want to dwell on what went wrong and a positive evaluation is more useful than a negative one when it comes to raising money for the next project. However, in the long run, unbalanced evaluations are no use to anyone.

(Shaw, 2002:10)

There seems to be a less than perfect fit between factors highlighted in policy terms by the Social Exclusion Unit (e.g. poor health and housing, low educational attainment, high crime and unemployment rates), and the understandings which gallery and museum staff bring to activities intended to combat social exclusion. Research at the Universities of Newcastle and Stirling found

Very little clarity about what the profession sees as social exclusion. Many curators said they had been doing this work for years and felt it was similar to access and audience development. Some said social inclusion was something that happened naturally when people came into museums. But there was little discussion of the concept in wider terms and how this process might occur.

(Newman, 2001: 35)

For cultural organizations 'the meaning, significance and implications of social exclusion and inclusion have been fluid, evolving and problematic' (Sandell, 2003: 45). Though some have seen the UK approach as 'a disturbing attempt at social control', this author argues that museums and other cultural organizations can empower individuals and communities and work to combat multiple forms of disadvantage. However he says that though these new roles seem to some 'an inappropriate departure' from museums' traditional roles, others are enthusiastic about the opportunities they offer, observing too that some museums 'have been individually working in this way for many years' (Sandell, 2003: 48).

Against barriers, uncertainties and misalignments such as those outlined above, it is important for the evaluation exercise to document as far as possible the distinctive contribution of each of the En-vision pilot action research projects to help improve our understanding of such work within the sector.

\section{Some issues in evaluating inclusion projects}

En-vision projects are supported directly by the national programme development coordinator, covering both management of the projects and evaluation activity. For everyone involved in the pilots, En-vision raises challenges and some galleries have been learning to work with new partners as well as with young people. Some bring to the pilot programme 
expertise in evaluating projects, but for others, action research and formal evaluation has been a novel experience. identified

Among the inhibitors to change in local authority museums, Sandell (2003:52)

Firstly, and most significantly, a resistance to change that is manifest within entrenched attitudes amongst museum workers. Though there has been little empirical research into the attitudes and values of museum staff, that which does exist suggests that most do not subscribe to the notion that museums have a social responsibility to tackle issues of inequality and disadvantage.

He notes also the attitudes which others have towards museums, claiming that they are 'rarely considered as appropriate partners by social, welfare or health agencies'. Observations about 'museums' may not necessarily apply in exactly the same way to galleries which show mainly contemporary work in temporary exhibitions; moreover those gallery staff who chose to work with En-vision tend to be people already committed to and working for wider access. However, the general point about contact with other agencies is relevant: the energy required to forge new partnerships has been a dominating feature of some En-vision pilots.

The evaluation approach (and budget) in En-vision emphasised the role of internal evaluation, by practitioners and young participants. Our role as external evaluation partners at the University of Warwick has been to design an overall framework, provide support to internal evaluators and independently collect additional evidence from project leaders to advance understanding of the process, the achievements of projects and of En-vision as a whole. The research partnership between practitioners and evaluators is a creative and flexible one which leaves space for negotiation.

Mindful of the barriers which distance young people from activities in galleries, the evaluation seeks to capture what barriers participants may identify at the start of their involvement in the projects, ways in which their attitudes change during and their views towards the end of the projects. Project leaders are encouraged to collect information from young people at an early stage and at the end.

The literature suggests practical ways in which young people think galleries and museums might be more appealing (Selwood et al., 1995; Elliot, 2000). Such sources indicate that they also want access to adults, both artists and others working there. The Envision pilots give the chance to record how this operates in practice and how such relationships may affect the opinions of participants. Youth art workers, artists, gallery education staff, design and marketing staff are involved. One pilot includes a mentoring scheme. Intergenerational interaction and relationships between different professional groups mean that the impact of En-vision is not one-way or even two-way, but far more complex. Early findings certainly indicate that gallery staff are learning from their contact with young people and also from observing artists working with young participants.

Innovative schemes sometimes produce exciting and unforeseen developments. They can also encounter 'teething problems'. Moving beyond these contributes to organizational development and professional expertise. In any field, the identification of training needs may be an unsettling experience (Galloway, 2000). It has been suggested that engaging with certain groups of young people outside formal education can provoke fear of cultural democracy when 'the cultural gatekeepers dread the questioning of their assumptions about the arts - what belongs in it and what is beyond the pale' (Ings, 1999: 28). But reflection on professional practice is rarely a tidy or simple process (Schön, 1983) and a positive organizational culture supports staff in working through uncertainties and feeding back the professional learning from the individual to benefit the organization.

One aspect of En-vision is how gallery staff generally are being alerted to ways of working with young people who may sometimes prove challenging. This issue was addressed at a national conference for En-vision project leaders several of whom later provided training for their colleagues. In practice there may still be awkward moments as in one (ultimately very successful) project which initially encountered sensitivities between gallery staff and young participants. Interviews conducted by the young people with gallery 
staff were the means of resolving this, along with an agreement about the most suitable location for participants' smoking breaks.

Engage's earlier 'encompass' programme also involved young people in gallery based projects. The evaluation was shared between internal and external teams and the report (RCMG, 2000) confirms that a hybrid methodology of internal and external evaluation can combine the rigour of documented evidence with the authenticity of the voices of those involved. Evaluation of the En-vision programme sought to move further by giving an enhanced role to young participants, to increase the stock and richness of evidence and develop their capacity to evaluate their experiences. In practice, this degree of participant involvement has proved hard for some projects to achieve primarily because of time and other logistical constraints. Similar issues have been recorded in comparable projects (Pontin and Hawthorne, n.d.).

The evaluation challenges concern how simultaneously to maximise the diversity of evaluative approach and evaluative democracy between and within projects and, at the final stage, how to synthesise this material to support conclusions about the En-vision programme as a whole.

\section{A Menu of Methods}

Recognizing the substantial role which self-evaluation would play in En-vision, we sought methods which would be accessible to all parties: project leaders, the programme's development co-ordinator and the young people. At the same time the approach had to be sufficiently sophisticated to reflect the complexity of these projects and be capable of further validation. We suggested various creative methods, and this menu was negotiated with the programme's development co-ordinator and pilot project leaders, leading to an overall agreement with some scope for variation between projects. The En-vision development coordinator subsequently summarised these suggestions, from which project leaders chose whichever methods were practicable in their case:

- Group interviews/focus groups, group reviews of e.g. young people only, or including participant adults.

- Individual discussions, interviews.

- 'Press conference' style sessions, roving reporters.

- 'Expert panels' or 'round tables'.

- Collective notice boards, storyboards, graffiti walls, comments boxes or a 'tree of thoughts' (Yoko Ono piece of work - info provided).

- Young people's diaries, logs, scrapbooks (individual and group).

- Participatory techniques, e.g. role-play, drama, games, visualisation, drawings, diagrams.

- Video booths, documentary style videos providing commentary material/and or responses and recommendations.

- Observation (NB need for focus, structure to produce useful information).

- Use of photographs and artefacts to trigger recollections and encourage analytical skills.

- Young people presenting findings/responses at interim stages on a work-inprogress basis through presentations, reviews, display or multi-media.

- Suggestions for documenting the data include note-taking, photography, using audio or video recording, visual means such as sketches, cartoons, charts, maps or diagrams. It is important to date information to chart progress/finings, even if it is anonymous (e.g. post its or postcards for a collective display of comments to be colour coded on a weekly basis). 
- It is anticipated that pilots will plan review meetings at key points to focus on emerging issues and progress. It is recommended that these are minuted.

- It is recommended that where possible or appropriate staff involved keep an evaluation diary with notes on substance and methods and analytical comments.

(Engage, August 2003)

Such approaches can involve everyone, do not rely on written material alone, and are (mostly) inexpensive. They align with the approach set out in Woolf (1999) and allow for creative elements in the evaluation process, in keeping with the pilot projects themselves (Simons and McCormack, 2002; Goodlad, Hamilton and Taylor, 2002). They respect the distinctive nature of the separate projects.

Alongside the possibilities outlined above, a coherent framework was provided with a crosscutting element to draw out generic features of the programme. Each project leader completes a standard progress log at intervals and a final report form. Members of the project staff were consulted about interview schedules for use with participants, and in the event, several have, as we envisaged, given young people the chance to conduct the interviews in pairs, and have filmed these. Where a project intends to create a web site, this provides material which be edited for that, so these interviews serve a dual purpose. (However, converting the filmed data to information on paper which can be analysed and compared with that coming from other projects is another task altogether.)

We ourselves conduct interviews with project leaders at an early stage and at the end of their project. Central to this evaluation process is the need to reconcile the twin imperatives of, on the one hand, particular, bottom up diversity and, on the other, overarching consistency and rigour. Both perspectives are needed to give as full a picture as possible of how these projects and the programme overall are addressing the social inclusion agenda.

\section{Some issues emerging in evaluating En-vision}

The En-vision programme sets high aims. It provides support and it makes demands of those involved. It has already produced some telling outcomes for certain young people. In terms of evaluation too, experience gained in the pilot projects will feed into future work in this area.

One example is where, to encourage feedback from young people, one project team used small coloured paper swatches. Each participant created an individual collage to reflect their experience in the course of their day at the gallery. This visual medium triggers reflection and helps them articulate their views. So successful was the method that project staff now replicate it on other occasions. This example shows how a particular technique can stimulate information which is rich and detailed, giving good feedback on the session and useful for internal project evaluation. However this cannot be standardised across projects so is of less value for the overall programme evaluation. It can only contribute to a broader analysis if the explanation given by the creator of the collage is recorded so that this could be reviewed alongside comments made by others. Even then, this is very context-specific and subjective material; moreover capturing and analysing qualitative data in this way has resource implications.

In evaluating projects, some effects can only be recorded through close observation (which may be by those who know the young people well) or through in-depth interviews. Evidence of this sort, whether gained as part of the internal evaluation from project partners or through interviews conducted by the external evaluation partners, can be strong testimony to a project's value. Already there are cases where the experience of En-vision is providing notable turning points for young people. These cannot be easily quantified but deserve to be documented. The evaluation process has provided a framework for logging such achievements and equally for recording the pitfalls encountered and lessons for further development.

More general issues emerging in the first year concern discontinuity because of changes in partners (both organizations and individual contacts) and delays relating to the recruitment of young people. However committed partners are, time pressures in managing and delivering activities have affected most projects; in some cases, coping with these 
matters has led to lower priority for evaluation. However the fruits of the pilots are now appearing and will be reported in 2005. The outcomes will be disseminated to practitioners through Engage's national and international network and other channels (Engage, 2004).

\section{Concluding Comments}

In 'The Shape of Things to Come?' Anderson (2000) considers what is known about young people's attitudes to galleries. Two points relate especially to the issues raised in this article. First, there is the suggestion that,

The absence of young people from museums is not itself the 'problem' (if, indeed, it is accepted that there is a problem). Rather, it is a symptom - albeit the most conspicuous one - of something wrong with museums as we have them today. This is a cultural and philosophical matter, not a demographic one. It is something that affects every visitor, not just young people.... it is museums themselves, rather than their provision for young people, that would have to change.

Anderson, 2000: 163

Secondly, this author questions how far an institution can realistically meet multiple aims, given the deep cultural divisions in our society, and suggests that museums may be forced to make choices. This might mean representing certain groups and accepting that other audiences may be lost as a result (Anderson, 2000: 165). Such diverse missions provide very different contexts for evaluation which is inevitably designed within a given political or management context.

Many commentators stress the constraints of the political climate within which galleries and museums operate, and we have seen something of this in the two programmes discussed above. In evaluating these we have at times been aware of 'entrenched' attitudes in the sector but equally among project leaders and their partners we have seen an openminded flexibility towards exploring new directions and a growing recognition of how appropriate evidence can validate work in museums and galleries.

In some camps, evaluation is perceived as in some sense a management tool, to encourage, engage and hold accountable the actors involved in delivering the programme and to inform policy and programme decisions. This, it is argued, is inevitable when the agencies responsible are allocating large sums of public money and museum staffs are required to monitor and account for its use.

Some others justify the same activities as a 'good experience' and remain sceptical about the extent to which the particular and individual experiences of participants can be aggregated, analysed and compared. Nevertheless, even amongst those who share some of this scepticism, there are practitioners in museums and galleries who want to articulate for other practitioners the value of these experiences and their more complex significance. There also appear to be a growing number ready to equip themselves with the appropriate techniques and to work in partnership with researchers, so as to interpret and convey those experiences in ways which will answer questions which others - outside their profession are asking.

Both programmes discussed here have strong elements of self-evaluation and negotiated evaluation, where the evaluation process is tailored to allow for the distinctive goals, preferences and outputs of the activity. This is not a mere concession to win cooperation. It would be a backward step if, in the 'treasure hunt' for educational and social gains, evaluation reports were to disregard some unanticipated gains or over-emphasize generic outcomes at the cost of very specific outcomes. Through the authenticity of in-depth qualitative data, the analysis can try to capture, for instance, what it is that a gallery per se offers, compared with other possible locations for work with excluded young people.

Inevitably in any field there are elements of 'partisan' evaluation for reasons encapsulated earlier (Shaw, 2002: 10). Moral hazard attaches to evaluation driven by budgets and the need to make a case for the next bid for funding. Here too, a combination of internal 
and external evaluation can be useful, offering reciprocal checks and balances.

New educational and social objectives for museums and galleries arise when these institutions respond to opportunities to join with new partners to tackle specific political or social priorities. It is partly the diversity and flexibility of museums and galleries which make them capable of seizing the opportunity (and funding) to take on these new objectives. They bring new perspectives and approaches to bear on educational and social issues - which is, of course, one reason why public and private funding bodies believe that they have a contribution to make. This creates new challenges for evaluation, whether it is internal, by curators, education or outreach officers, or external, by independent researchers.

However, these new perspectives and diversity in approach require extremely responsive and inclusive evaluation if justice is to be done to the variety of activity. The new objectives require the forging of new partnerships between museums and galleries on the one hand and educational and social organizations or groups on the other. This implies an additional negotiation and customisation of purpose and of process and this customisation can have the effect of fragmenting a programme into a set of separate partnerships. Nevertheless, sponsors and institutions themselves have an interest in the overall performance of the programme and to provide this ways have to be developed to put together outcomes, whether educational or social, from different projects and partnerships.

Evaluation of the Museums and Galleries Education Programme Phase 2 and the Envision pilot programme, where professional museum and gallery staff are encouraged to 'think outside the box' is now feeding into the new initiatives which we outlined earlier and into the education policies which museums and galleries have, or are currently developing, for forthcoming initiatives relating to cultural entitlement.

\section{Acknowledgements}

We have gained much from discussions with those associated with these programmes, including representatives of DfES, the Museums, Libraries and Archives Council, and Engage. Regional officers, museum staff, teachers, pupils, artists and other participants have helped our understanding, as did Warwick colleagues (Mairi Ann Cullen in CEDAR, Professor Prue Huddleston and others in CEI), along with Andrew Newman of Newcastle University, and Sue Clive. Earlier versions of this paper were presented at the 2003 Annual Conference of the UK Evaluation Society and the 2004 International Conference of the Centre for Educational Development, Appraisal and Research.We much appreciate the comments of participants at those sessions and, also, recent discussion with Gordon Fyfe about this article.

\section{Notes}

1 http://www.teachernet.gov.uk/museums

2 http://www.teachernet.gov.uk/mgep2

3 The nine regional offices of the Museums, Libraries and Archives Council cover: East of England, East Midlands, North East, North West, South East, South West, West Midlands, Yorkshire and the London Museums Agency.

${ }^{4}$ http://www.teachernet.gov.uk/mgep2

${ }^{5}$ http://www.en-vision.org.uk 


\section{References}

Anderson, D. (2000) 'The Shape of Things to Come' in N. Horlock (Ed.) Testing the Water. Young People and Galleries, Liverpool: Liverpool University Press and Tate Gallery Liverpool 159-166.

Anderson, D. (1997a) A Common Wealth. Museums and Learning in the United Kingdom. Report to the Department of National Heritage, (January) London: Department for National Heritage.

Anderson, D. (1997b) 'Time to Jump into the Learning Loop', Museums Journal, November.

Arts Council of England (1998) Cultural Diversity Action Plan, London: ACE.

Arts Council of England (1994) Youth Audience Research Report, London: ACE.

Centre for Education and Industry (2004) Interim Report on the Museums and Galleries Education Programme Phase 2, Coventry, CEI University of Warwick and http:// www.teachernet.gov.uk

Department for Culture, Media and Sport (2003) Learning to Listen Core Principles for the Involvement of Children and Young People: A review of progress made and new developments for 2003, London: DCMS.

Department for Culture, Media and Sport (2000) Centres for Social Change: Museums, Galleries and Archives for All, London: DCMS.

Department for Culture, Media and Sport and Department for Education and Employment (1999) All Our Futures: Creativity, Culture and Education Report of the National Advisory Committee on Creative and Cultural Education, London: DfEE.

Department for Culture, Media and Sport and Department for Education and Employment (2000) The Learning Power of Museums: A Vision for Museum Education. London: DCMS.

Department for Culture, Media and Sport (1999) Policy Action Team 10: A Report to the Social Exclusions Unit - Arts and Sports, London: DCMS.

Department for Education and Skills (2003) Learning Through Culture. Information leaflet on the Museums and Galleries Education Programme Phase 2.

Economou, M. (2004) 'Evaluation Strategies in the Cultural Sector: the Case of the Kelvingrove Museum and Art Gallery in Glasgow', Museum and Society, 2 (1) (March) 30-46.

Elliot, J. 'Ten Things Young People Say about the Experience of Art Galleries, and Ten Changes Young People Ask of Art Galleries', in N.Horlock (Ed) Testing the Water Young People and Galleries, Liverpool, Liverpool University Press and Tate gallery Liverpool 20-21.

Engage (2004) 'The en-vision Pilot Programme', Symposium presenting project reports and evaluation approach at the Opening Doors and Museums Association Conference, Church House, Westminster, $14^{\text {th }}$ June.

Engage (2003) 'Evaluation plan for en-vision project leaders', August.

Galloway, S., Lindley. R., Davies, R. and Scheibl, F. (2002) A Balancing Act: Artists' Labour Markets and the Tax and Benefit Systems, Research Report 29, London: Arts Council England. 
Galloway, S. (2000) Continuing Professional Development: Looking Ahead Oxford: ESRC's Research Centre on Skills, Knowledge and Organizational Performance.

Garnham, N. (2001) 'Afterword: The Cultural Commodity and Cultural Policy' in S. Selwood (Ed) The UK Cultural Sector. Profile and Policy Issues, 445-458.

Goodlad, R., Hamilton, C. and Taylor, P. (2002) "Not Just a Treat": Issues in evaluating arts programmes to secure social inclusion' UK Evaluation Society Annual Conference, The Art of Evaluation: Artistry, Discipline and Delivery, London, 12-13 December.

Harland, J. and Kinder, K., (Eds) 2000 Crossing the Line, Extending Young People's Access to Cultural Venues London: Calouste Gulbenkian Foundation, The Arts Council of England, National Association for Educational Research.

Harland, J., Kinder, K., Lord, P., Stott, A., Schagen, I. and Haynes, J. with Cusworth, L., White, R. and Paola, R. (2000) Arts Education in Secondary Schools: Effects and Effectiveness, Slough: NFER.

Harland, J., Kinder, K. and Hartley, K. (1995) Arts in Their View. A Study of Youth Participation in the Arts, Slough: NFER.

Hawthorne, E. (Ed) n.d. 'Museum Fever and Represent: Lessons for Working with Young People in Museums'. Research Report for Resource, the Council for Museums, Archives and Libraries.

Hooper-Greenhill, E. (2004) 'Measuring Learning Outcomes in Museums, Archives and libraries: the Learning Impact Research project (LIRP), International Journal of Heritage Studies, 10, 2 (May), 151-174.

Incomes Data Services (2004) Pay in Museums Research Report for the Museums Association (March).

Ings, R. (2001) funky on your flyer a report on the Crossing the Line Seminars, London: Arts Council of England.

Kawashima, N. (1997) 'Museum Management in a Time of Change. Impacts of Cultural Policy on Museums in Britain 1979-1997'. Coventry: Centre for the Study of Cultural Policy, University of Warwick.

Kinder, K. and Harland, J. (2004) 'The Arts and Social Inclusion: What's the Evidence?', British Journal of Learning Support, 19 (2), May, 52-56.

Kinder, K. and Wilkin, A. (1998) With All Respect: Reviewing Disaffection Strategies, Slough: NFER.

Lawley, I. (2003) 'Local Authority Museums and the Modernizing Government Agenda in England', Museum and Society, 1 (2), 75-86.

Matarrasso, F. (1997) Use or Ornament? The Social Impact of Participation in the Arts, Stroud: Comedia.

Mayrand, (1985) 'The New Museology Proclaimed' Museum 32 (4): 200-201.

Newman, A. (2002) ‘Feelgood Factor’, Museums Journal, May 2002, 29-31.

Newman, A. (2001) 'Social Exclusion Zone', Museums Journal, Sept 2001, 34-36. 
Office of Arts and Libraries (1991) Volunteers in Museums and Heritage Organizations. Policy, Planning and Management, London: HMSO.

Reeves, M. (2002) Measuring the Economic and Social Impact of the Arts, London: Arts Council England.

Research Centre for Museums and Galleries (2002) 'The Impact of the DfES 'Museum and Gallery Education Programme'. Leicester: RCMG.

Research Centre for Museums and Galleries (2000) 'Encompass Evaluation Report' Leicester: RCMG.

Richey, S. (2004) 'Promoting Social Inclusion through the Arts', British Journal of Learning Support, 19, 2, (May) 50-51.

Sandell, R. (2003) 'Social Inclusion, the Museum and the Dynamics of Sectoral Change', Museum and Society, 1 (1) 45-62.

Schön, D.A. (1983) The Reflective Practitioner, New York: Basic Books.

Selwood, S. (Ed.) (2001a) The UK Cultural Sector. Profile and Policy Issues, London: Policy Studies Institute.

Selwood S. (2001b) 'Introduction and Observations' in S. Selwood (Ed.), The UK Cultural Sector. Profile and Policy Issues 1-3.

Selwood, S. (2001c) 'Museums and Galleries' in S. Selwood (Ed.) The UK Cultural Sector. Profile and Policy Issues 22-25.

Selwood, S. (2001d) 'Profile of Museums and Galleries' in S. Selwood (Ed.), The UK Cultural Sector. Profile and Policy Issues 342-359.

Selwood, S., Clive, S. and Irving, D. (1995) An Enquiry into Young People and Art Galleries, London, Art and Society.

Shaw, P. (2002) 'Home Truths', engage review Issue 11, Summer 2002, 8-11.

Simons, H. and McCormack, B. (2002) 'Arts-based inquiry: the challenges for evaluation' UK Evaluation Society Annual Conference, The Art of Evaluation: Artistry, Discipline and Delivery. South Bank Centre, London 12-13 ${ }^{\text {th }}$ December.

Stanley, J. (2003) Note on Learning Outcomes, MGEP2 project document, May.

Vergo, P. (Ed.) (1989) The New Museology, London, Routledge.

Willis, P. (1990) Moving Culture: An Enquiry into the Cultural Activities of Young People, London: Calouste Gulbenkian Foundation.

Woolf, F. (1999) Partnerships for Learning. A Guide to Evaluating Arts Education Projects, London, Arts Council of England. 
*Sheila Galloway is a Senior Research Fellow in the Centre for Educational Development, Appraisal and Research at the University of Warwick. She has researched and published widely on continuing professional development in education and other occupations and on the cultural sector, recently on artists' labour markets and the evaluation of the national Dance and Drama Award Scheme.

Julian Stanley is a Regional Director of the Centre for Education and Industry at the University of Warwick. He managed the project to evaluate the Museum and Gallery Education Programme Phase 2. He is currently collaborating with Sheila Galloway on work relating to Tate Modern's Youth Programme.

\section{Addresses}

Dr Sheila Galloway

Senior Research Fellow,

Centre for Educational Development, Appraisal and Research.

University of Warwick,

Coventry CV4 7AL

Tel: +44 (0) 2476522196

Fax: +44 (0) 2476524472

Email: Sheila.Galloway@warwick.ac.uk

Julian Stanley

Regional Director,

Centre for Education and Industry,

University of Warwick,

Coventry CV4 7AL

Tel and Fax: +44 (0) 2089235679

Email: J.A.Stanley@warwick.ac.uk 